\title{
The Diversity of Seed-Saving Governance and Sharing Systems in contemporary Japan
}

\author{
Ayako Kawai
}

\begin{abstract}
Crop diversity in Japan is on the ebb, eroded by factors such as the rise of industrialised agriculture, a shrinking and ageing population of farmers, and a dearth of knowledge transmission between generations. However, thousands of Japanese farmers follow a practice vital to fostering agrobiodiversity: seed saving. Using a qualitative case study approach, Ayako Kawai tracked diverse seed governance and sharing systems across four groups of producers: traditional, organic and 'lifestyle' farmers and local community members. She found differences in the ways seeds are valued-cultural, economic, rights-based, familial or personal-that influence approaches to saving and sharing seeds. Organic and traditional farmers and community growers, for instance, tightly regulate seed distribution, while part-time producers are far keener to actively share seeds. That could, notes Kawai, create a dilemma if broader access to genetic resources becomes a general priority. Yet she concludes that a plurality of practices, like crop diversity itself, builds in resilience by spreading risk and offering a range of responses to future uncertainties.
\end{abstract}

\section{A. Kawai $(\bowtie)$}

Research Institute for Humanity and Nature, Kyoto, Japan

Y. Nishikawa and M. Pimbert (eds.), Seeds for Diversity and Inclusion, https://doi.org/10.1007/978-3-030-89405-4_5 
Keywords Intellectual property rights - Seed saving governance · Seed sharing $\cdot$ Trust . Values

\subsection{INTRODUCTION}

The availability of seeds, and the way farmers access them, are key to the success of agrobiodiversity conservation and management (Hodgkin et al., 2007; Jarvis et al., 2011). And informal seed systems are important in this context: they are generally recognised as helping to maintain agrobiodiversity as well as providing farmers with better access to seeds (FAO, 2010). Yet the socio-cultural factors involved in seed distribution under such systems, such as social ties, social status and cultural norms (Badstue et al., 2006; Jarvis et al., 2011), have to date been largely ignored by researchers.

In Japan, the rise of agricultural industrialisation is damaging crop diversity. Since the 1960s, government policy reform has facilitated monocultural mass vegetable production and replaced local varieties with commercial hybrids. The limited market value of local varieties and the fall in numbers of farmers have further contributed to the loss of crop diversity (FAO, 2010). As in Italy (Negri, 2003) and other developed countries (Pautasso et al., 2013), the farmers who save local varieties in Japan constitute an ageing population; the limited transmission of their knowledge to younger generations poses another challenge for the conservation of local varieties. While public interest in agrobiodiversity is rising gradually in response to recent changes in seed-related laws, little is known about seed saving in Japan-neither the groups involved, nor the values that motivate them.

This chapter aims to redress the balance by exploring the values and motivations of Japanese seed savers, with particular focus on seed sharing. I compare four types of seed savers:

- traditional farmers (those who have received seeds and learned seed saving from their family members)

- non-traditional local community members

- full-time organic farmers

- lifestyle farmers (those who farm as a lifestyle choice and do not derive the majority of their income from farming). 
Since no survey has been conducted in Japan to gauge the number of seed savers, it is difficult to provide a breakdown of the different groups engaging in the practice across the country. According to data reported by the Japan Organic Agriculture Association (JOAA, 2010) and Mokichi Okada Association Nature Farming and Culture Foundation (MOA, 2011), ${ }^{1}$ however, some 7200 organic farmers in Japan save seeds.

This research is based on a qualitative case study approach, involving 62 semi-structured interviews and 44 days of participant observations in 14 prefectures across Japan through 2016-2018. My findings are as follows.

\subsection{Traditional Farmers}

I found that traditional farmers save heirloom seeds, learning the skills from family members. They regarded seeds received from parents or inlaws as an ancestral heritage, motivating them to continue in the practice. For instance, some traditional farmers in Akka hamlet, Iwate prefecture, were committed to saving seeds because they saw them as such an inheritance from their ancestors. They felt that they should not tayasu (relinquish) those seeds: that would be an abdication of responsibility, and would mean the end of that variety.

Hiroaki Egashira, an academic and the president of a local cropdiversity conservation group, also noted during an interview that some traditional farmers continue to save seed in Yamagata prefecture because they "feel sorry for ancestors, losing what they have transmitted from generation to generation". Similarly, Kazuya Takahashi, a merchant specialising in traditional vegetables, reported that many traditional farmers felt deeply responsible for maintaining inherited seeds. Some, Takahashi noted, said that the person who first saved the seed "entrusted the seeds" to them, and that the seeds reminded them of the ancestral seed saver's face.

Traditional farmers often restricted their distribution of heirloom seeds. The most extreme cases were farmers who saw seeds as mongai-fushutsu

1 The MOA (2011) estimated the number of full-time organic farming households across Japan as 12,000 . The JOAA (2010) reported that $60 \%$ out of 155 interviewed organic farmers save vegetable seeds. I estimated the number of seed-saving full-time organic farmers by multiplying 12,000 by 0.6 . 
(meaning never given to others), except in regard to family members. For example, Kurofuji-kyūri, a variety of cucumber, has been maintained by an individual in Yamagata prefecture who has been faithful to the precept that it be conserved only by family members (Egashira, personal communication). Even without such explicit family rules, traditional farmers tend to feel hesitant about sharing their seeds. Takahashi observed that it was often difficult for non-traditional local savers to acquire seeds while the traditional farmers saving them were still living. Even within the local community, seed sharing was found to be patchy.

Reports of disrespectful acts by people receiving seeds also made traditional farmers cautious about extending their sharing more widely. In Iwate prefecture, for example, one person who received seeds of a local turnip variety registered a trademark for it using its recognised regional name. That act effectively prevented traditional farmers from selling their turnips under the name, resulting in a loss of potential income.

This study's finding that traditional farmers valued seed saving largely because of the ancestral connection echoes others in South Africa (van Niekerk \& Wynberg, 2017) and Peru (Tobin et al., 2018). But it also reflects a narrative of ancestor worship and related obligations that is deeply rooted in Japanese culture, especially within the traditional family system. The challenge for traditional farmers to find a successor may not only be an issue to do with human resources. It also points to the fact that younger generations do not place the same significance on the narrative of ancestoral connection, leading to diminished motivation for saving heirloom seeds. Because of this trend, the transmission of seeds and knowledge from traditional farmers to the younger generation is an even more pressing issue.

Yet some traditional farmers have found ways of surmounting such barriers. For example, in Yamagata prefecture some traditional farmers who were ageing, and had no family members willing to continue cultivation, started to openly share their mongai-fushutsu seeds with local community members (Egashira, personal communication). As familial transmission ebbs, the significance of local community members' interest in conserving local varieties has increased. 


\subsection{Non-Traditional Local Community Members}

In this group-non-traditional local community members saving local varieties of seeds transmitted outside their families-those I interviewed tended to receive the seeds from traditional farmers or, in some cases, gene banks or seed companies. Individuals in this group valued local varieties because it strengthened their identity by effectively connecting them to local cultural history.

Some I interviewed valued local variety seeds because of their part in conserving local culture and traditional landscapes. Akari, head of the local variety conservation group in Akka hamlet, felt that the surrounding landscape would be irrevocably altered if farmers stopped cultivating local varieties, and started seed saving on her own. Similarly, locals in Aomori prefecture revived the cultivation of a local spring onion variety, feeling that it represents local identity. Their stated goal was to "ensure that children in one hundred years can proudly say 'This is our spring onion"”. One interviewee regarded such varieties as teaching materials, allowing young people to recognise local assets and meet those keen to protect them. He also noted that such learning fostered students' attachment to their hometown. Local varieties are thus strongly tied to regionalism and local identity.

Within the non-traditional local community, people often limited seed distribution to non-community members for a range of reasons: to maintain a price premium, protect the unique character of the region, or ensure high-quality production. In Aomori prefecture, a small number of contracted farmers handled seed distribution as a way of maintaining a premium price. They found it challenging to make a living from producing local varieties, and so generated higher profits by restricting the number of growers (and so the overall size of harvests), which rendered the variety exclusive. In Iwate prefecture, Akari designated seeds of the radish Akka daikon mongai-fushutsu, restricting seed sharing to residents of the hamlet. Very few of the resident farmers still cultivate it, which led Akari to fear that growers elsewhere might take up the variety-and so erode its unique connection to Akka. Interestingly, traditional farmers I spoke to, however, did not restrict seed sharing to this degree.

In Tokyo, one founder of a local variety conservation group restricted the distribution of local seed varieties and seedlings to locals. He thought it irresponsible to casually give away seeds because it was important to harvest "the original fruits". He commissioned local professional farmers 
to grow and reproduce the varieties distributed. In general, people I interviewed within this group valued the authenticity and uniqueness of a variety, so they restricted access to them to protect those values.

The people I interviewed in this overall group often created their own rules to limit seed distribution, and sometimes asked traditional farmers to comply with them. Such rules allowed locals to protect their intellectual property rights, which are different from formal regulations that mainly protect professional plant breeders. For instance, an organic farmer I interviewed, from Morioka city in Iwate prefecture, was interested in saving seeds of the radish on from Akka, which is in his prefecture; but Akka's local conservation group leader claimed the radish seeds to be mongai-fushutsu, so the farmer could not ask for them. In this sense, informally agreed rules enabled locals to effectively protect their intellectual property rights by refusing outsiders access to the seeds.

\subsection{Organic Farmers}

Organic farmers are full-time working farmers who rely mainly on seed saving for their crops. Those I interviewed were highly interested in saving local variety seeds, but often struggled to find or access them. In some cases, local varieties have disappeared from their areas. They also reported that identifying and building trust with traditional seed savers was challenging. Given these difficulties, organic farmers sought local varieties from neighbouring regions or purchased non-hybrid seeds from seed companies.

Through saving seeds, organic farmers aimed to develop their own varieties adapted to local environmental conditions. One young farmer who sourced seeds of local varieties from local companies mentioned that once a variety developed new traits under cultivation, he would rename it using his own surname. Another, older organic farmer, who bred a variety highly praised by the owner of a seed company, was not willing to register it for intellectual property rights. He suggested that this was a norm among his fellow organic farmers.

The organic farmers I interviewed generally felt reluctant to distribute their seeds widely, fearing careless treatment. They preferred to entrust (takusu) seeds to those they had close relationships with. A person so trusted was responsible for taking good care of the seed and not distributing it widely either-to protect farmers' rights as well as their emotional attachment to their self-bred varieties. One farmer indicated 
that he was very concerned that the crops he gave to a trusted farmer "lived well". Like some other organic farmers, he effectively viewed the seeds as his children, and felt that it was his duty to ensure their wellbeing.

The seed-sharing strategy of organic farmers thus differed from those of traditional farmers, and of non-traditional community members. Still, their caution about distributing seeds functioned as a kind of informal protection of intellectual property rights. Organic and lifestyle farmers did not necessarily ascribe the same values as to seed sharing, for instance, and this created friction between them. Several organic farmers I interviewed mentioned that they felt disappointed when they shared seeds with casual savers who were not committed to the practice. A case showing a similar preference to give seeds to those enthusiastic about multiplying seeds was reported in South Africa (van Niekerk \& Wynberg, 2017).

\subsection{Lifestyle FARMers}

Lifestyle farmers engage in farming as a lifestyle choice, and do not earn major income from farming. Those I interviewed saw seed saving as a hobby and most did not show any special interest in saving the seeds of local varieties. They mainly bought seeds from seed companies or acquired them from informal exchange networks.

Lifestyle farmers that I interviewed followed natural farming methods ${ }^{2}$ that are reliant on ecological processes and minimise human interventions. Under this approach, they leave plants on farm after they wither, allowing the seeds to fall in situ; natural germination is highly valued. Since these farmers did not, strictly speaking, conduct plant selection or regard their activity as plant breeding, they were not concerned about wide seed distribution.

The interviewees casually shared seeds with friends and similar-minded people-a practice very different from the restrictive strategies of the other three farming groups studied. Unlike organic farmers, none of the lifestyle farmers mentioned a sense of responsibility to maintain seeds that they received from others; nor did they worry about the state of seeds given to others. This was partly because lifestyle farmers' full-time jobs prevented them from fully committing to farming. This group also produced more seeds than they could use, and preferred to give them to

2 Based on methods of the Japanese farmer-philosopher Fukuoka Masanobu, which were further developed by the farmer and author Yoshikazu Kawaguchi. 
others than to dispose of them-believing, with the other groups, that each seed is a living entity and must be treated with respect.

Lifestyle farmers' active seed sharing inspired many recipients to take up the practice. Yet in this context, these farmers' values and methods could also spark conflict. For example, one organic farmer mentioned it as problematic when seed receivers at seed-sharing events multiplied those seeds and subsequently shared them at other events. He noted that organic farmers donate their seeds, which are not registered, out of goodwill and in the expectation that receivers will not widely distribute them.

\subsection{Discussion AND Conclusion}

Sustainable seed management demands engagement by multiple actors. This study shows that seed saving in Japan is indeed carried out by multiple actors, each dealing with different types of seeds and conforming to different norms related to sharing them.

Figure 5.1 shows the four groups of Japanese seed savers introduced in this chapter, arranged according to two attributes: whether the act of sharing was open or restrictive, and whether the varieties maintained were integrated into local food culture, practices and traditions.

Fig. 5.1 Japanese seed savers: relative approaches to seed sharing, links to local culture

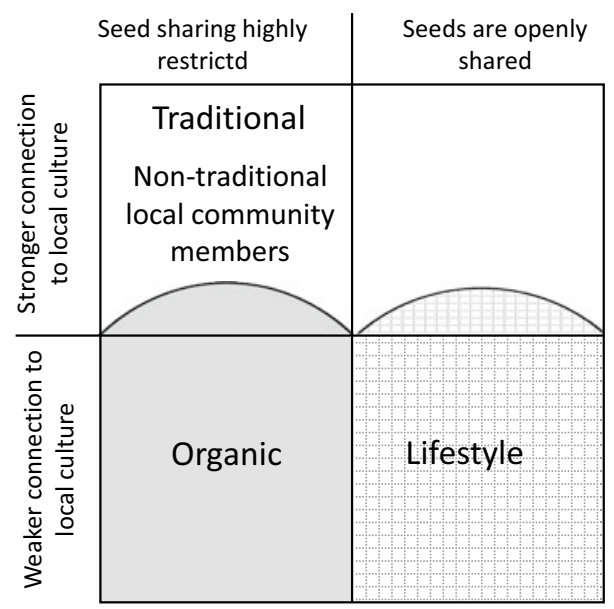


Lifestyle farmers were found to be keen to actively share seeds. While they concentrated primarily on non-local variety seeds, they also saved those of local varieties. By contrast, traditional farmers, non-traditional local community members and organic farmers followed norms and rules aimed at regulating seed distribution. Traditional and non-traditional local community members saved local varieties, while organic farmers saved both local and non-local. There were cases when farmers in the restrictive seed-sharing sphere occasionally widely shared their seeds, but these were exceptional and hence not reflected in the figure. (Open seed distribution of local variety seeds were sometimes carried out by local small seed companies, discussed in Chapter 10.)

The coexistence of diverse seed-saving practices with different rules and values reveals the plurality of seed governance. That diversity could in turn contribute to the conservation of crop diversity and food systems resilience in two ways.

The first is functional redundancy: by having multiple seed-saving practices, the loss of one could be compensated by others. While traditional farmers' practice in this regard was less likely to be sustained in the future compared with that of others, non-traditional community members and organic farmers were keen to save traditional farmers' seeds. The challenge lies in the restrictive seed-sharing attitudes and behaviours observed in traditional farmers, which could impede the effect of functional redundancy.

The second benefit of having diverse seed-saving practices is that in the face of future uncertainties, different groups of farmers may react in different ways. That range of responses could become a source of resilience. The four groups studied were on different economic footings (some saved seeds as part of their livelihoods, some not) and worked within different institutional settings (some were registered as farmers, some engaged in seed saving as an individual or as part of an organisation). Thus, different farmers may respond to the risks and challenges thrown up by ecological or social change in diverse ways. The farmers researched also had distinct motivations for saving seeds, and some were more committed to continue the practice than others. That may in turn influence the sustainability of each practice and the quality of genetic diversity maintained by each group of farmers in the context of future challenges.

My findings showed that trust is viewed as an important quality in seed receivers. Corresponding to the findings of Lone B. Badstue and 
colleagues (2007), and Jaci van Niekerk and Rachel Wynberg (2017), I found that seed transactions mainly took place between people with established social relationships. Some farmers and communities set stricter rules and memberships for seed transactions, often to protect savers' intellectual property rights regarding seeds. While having diverse seed exchange networks or social structures enhances the resilience of seed systems (Pautasso et al., 2013), this study showed that the plurality of seed governance may not necessarily ensure that farmers have better access to seeds.

The dynamic of different institutions and social networks influences the outcome of natural resource management (Bodin \& Crona, 2009). My research reveals tension and conflict between different groups of seed savers, hinging on differing attitudes to seed sharing and a lack of communication about those values. Identifying and openly expressing implicit values regarding seed sharing among diverse actors may facilitate better seed transmission within and beyond such groups.

It is important to highlight that Japanese farmers' resistance to broad seed sharing is intertwined with a strong sense of commitment to seed saving. This, however, creates a dilemma when they pursue agroecological values that aim to broaden access to genetic resources. Understanding farmers' values around seed saving, and the underlying socio-cultural context, is critically important in developing crop-diversity conservation measures that are effective, inclusive and resilient.

Acknowledgements The research has been supported partially by Research Institute for Humanity and Nature (RIHN: A constituent member of NIHU), FEAST Project (No. 14200116).

\section{REFERENCES}

Badstue, L. B., Bellon, M. R., Berthaud, J., Juárez, X., Rosas, I. M., Solano, A. M., \& Ramírez, A. (2006). Examining the role of collective action in an informal seed system: A case study from the Central Valleys of Oaxaca, Mexico. Human Ecology, 34, 249-273. https://doi.org/10.1007/s10745006-9016-2

Badstue, L. B., Bellon, M. R., Berthaud, J., Ramírez, A., Flores, D., \& Juárez, X. (2007). The dynamics of farmers' maize seed supply practices in the Central Valleys of Oaxaca, Mexico. World Development, 35, 1579-1593. https://doi. org/10.1016/j.worlddev.2006.05.023 
Bodin, O., \& Crona, B. I. (2009). The role of social networks in natural resource governance: What relational patterns make a difference? Global Environmental Change, 19, 366-374. https://doi.org/10.1016/j.gloenvcha.2009.05.002

FAO. (2010). The second report on the state of the world's plant genetic resources for food and agriculture. FAO.

Hodgkin, T., Rana, R., Tuxill, J., Didier, B., Subedi, A., Mar, I., ... Jarvis, D. (2007). Seed systems and crop genetic diversity in agroecosystems. In D. Jarvis, C. Padoch, \& D. Cooper (Eds.), Managing biodiversity in agricultural ecosystems (pp. 77-116). Columbia University Press.

Jarvis, D. I., Hodgkin, T., Sthapit, B. R., Fadda, C., \& Lopez-Noriega, I. (2011). An heuristic framework for identifying multiple ways of supporting the conservation and use of traditional crop varieties within the agricultural production system. Critical Reviews in Plant Sciences, 30, 125-176. https://doi.org/10. 1080/07352689.2011.554358

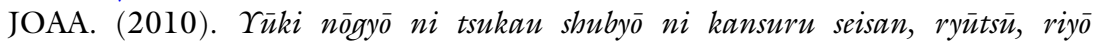
jittai chōsa bōkoku (2) - jika saisu wochūsin to shite [Report on the status of production, distribution and utilization of seeds and seedlings in organic farming (2)-Focusing on seed-saving]. Retrieved August 5, 2021, from https://www.197ljoaa.org/出版物-土と健康-書籍-dvd/調査事莱報告 書/\#houkoku06

MOA. (2011). Yūki nōgyō kiso dèta sakusei jïgȳo bōkokusho [Report on the project of gathering data on organic farming]. Retrieved August 5, 2021, from https://moaagri.or.jp/manage/wp-content/themes/moaagri/pdf/hoj ojigyo/H22_yukikiso_houkokusho.pdf

Negri, V. (2003). Landraces in central Italy: Where and why they are conserved and perspectives for their on-farm conservation. Genetic Resources and Crop Evolution, 50, 871-885. https://doi.org/10.1023/A:1025933613279

Pautasso, M., Aistara, G., Barnaud, A., Caillon, S., Clouvel, P., Coomes, O. T., ... Tramontini, S. (2013). Seed exchange networks for agrobiodiversity conservation: A review. Agronomy for Sustainable Development, 33, 151-175. https://doi.org/10.1007/s13593-012-0089-6

Tobin, D., Bates, R., Brennan, M., \& Gill, T. (2018). Peru potato potential: Biodiversity conservation and value chain development. Renewable Agriculture and Food Systems, 33, 19-32. https://doi.org/10.1017/S17421705160 00284

van Niekerk, J., \& Wynberg, R. (2017). Traditional seed and exchange systems cement social relations and provide a safety net: A case study from KwaZuluNatal, South Africa. Agroecology and Sustainable Food Systems, 38(8), 861889. https://doi.org/10.1080/21683565.2017.1359738 
Open Access This chapter is licensed under the terms of the Creative Commons Attribution 4.0 International License (http://creativecommons.org/licenses/ by/4.0/), which permits use, sharing, adaptation, distribution and reproduction in any medium or format, as long as you give appropriate credit to the original author(s) and the source, provide a link to the Creative Commons license and indicate if changes were made.

The images or other third party material in this chapter are included in the chapter's Creative Commons license, unless indicated otherwise in a credit line to the material. If material is not included in the chapter's Creative Commons license and your intended use is not permitted by statutory regulation or exceeds the permitted use, you will need to obtain permission directly from the copyright holder.

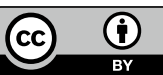

